\title{
Importance of antiresorptive therapies for patients with bone metastases from solid tumors
}

This article was published in the following Dove Press journal:

Cancer Management and Research

10 September 2012

Number of times this article has been viewed

\author{
Draupadi B Talreja \\ Department of Medicine, David \\ Geffen School of Medicine at UCLA \\ and Northridge Hospital Medical \\ Center, Northridge, CA, USA
}

\begin{abstract}
Patients with bone metastases are at risk of skeletal-related events such as pathologic fractures, spinal cord compression, the need for orthopedic surgery to bone, and palliative radiotherapy for severe bone pain. Antiresorptive therapies have demonstrated efficacy for reducing the risk of skeletal-related events and ameliorating bone pain. Despite the well documented clinical benefits of antiresorptive therapies, patient benefits can be limited or compromised by nonadherence with scheduled therapy. Potential reasons for poor compliance include lack of understanding of how antiresorptive therapies work, neglecting the importance of bone health in maintaining quality of life, and being unaware of the potentially debilitating effects of skeletalrelated events caused by bone metastases. Indeed, patients may stop therapy after bone pain subsides or discontinue due to generally mild and usually manageable adverse events, leaving them at an increased risk of developing skeletal-related events. In addition, the cost of antiresorptive therapy can be a concern for many patients with cancer. Medical care for patients with cancer requires a coordinated effort between primary care physicians and oncologists. Patients' medical care teams can be leveraged to help educate them about the importance of adherence to antiresorptive therapy when cancer has metastasized to bone. Because primary care physicians generally have more contact with their patients than oncologists, they are in a unique position to understand patient perceptions and habits that may lead to noncompliance and to help educate patients about the benefits and risks of various antiresorptive therapies in the advanced cancer setting. Therefore, primary care physicians need to be aware of various mechanistic and clinical considerations regarding antiresorptive treatment options.
\end{abstract}

Keywords: antiresorptive therapy, bisphosphonates, bone metastases, cancer, denosumab, zoledronic acid

\section{Introduction}

Antiresorptive therapies are important for maintaining bone health in patients with cancer metastatic to bone. Bone metastases can have a markedly negative impact on skeletal health by disrupting normal bone metabolism and weakening the skeleton. Consequently, patients with bone metastases are at risk of skeletal-related events such as pathologic fractures, spinal cord compression, the need for orthopedic surgery to bone, and palliative radiotherapy for severe bone pain. ${ }^{1}$ Moreover, pathologic fractures in particular are associated with decreased survival. ${ }^{2,3}$ Fortunately, antiresorptive therapies have demonstrated efficacy for reducing the risk of skeletal-related events and ameliorating bone pain. ${ }^{4-10}$

Despite the well documented clinical benefits of antiresorptive therapies, patients may often limit the benefits they derive by not adhering to the planned 
treatment schedule. There are several potential causes of poor compliance. For example, many patients focus on primary anticancer therapy and may fail to realize the importance of bone health in maintaining quality of life. These patients have limited awareness of the frequency and potentially debilitating effects of skeletal-related events caused by bone metastases. Typically, this patient group may not realize the extent to which skeletal health may deteriorate and may not be driven to educate themselves about the mechanisms of action of antiresorptive therapies. This could potentially lead to patients stopping therapy after bone pain subsides, leaving them at an increased risk of developing skeletal-related events. Additionally, unpleasant, but usually manageable, adverse events can cause patients to discontinue therapy. For example, the acute-phase response (APR) associated with some antiresorptive therapies can cause flu-like symptoms. Although these symptoms can often be managed with prophylactic acetaminophen, without appropriate advice, they may discourage patients from continuing therapy. Finally, the cost of therapy can be a major concern for many patients with cancer.

The medical care team can play an important role in educating the patient regarding the importance of antiresorptive therapy when cancer has metastasized to bone. Medical care for patients with cancer requires coordinated effort between primary care physicians and oncologists. Patients usually have frequent contact with their primary care physicians, especially once their disease stabilizes. Therefore, primary care physicians are in a unique position to help educate their patients and should be educated on issues related to the mechanisms of action, costs, benefits, and safety considerations associated with antiresorptive therapy options (particularly denosumab and zoledronic acid, which have the broadest indications across several tumor types for patients with bone metastases). ${ }^{11,12}$ The purpose of this review is to bring the importance of bone health in patients with cancer to the forefront for physicians.

\section{Literature search methods and limitations}

Articles indexed on PubMed during the last 5 years were searched using the search terms zoledronic acid and denosumab in combination with bone metastases, cancer, cost, and compliance. Important studies were identified from the literature search, and were limited to bone metastasis studies. Publications or presentations regarding postmenopausal osteoporosis, aromatase-inhibitor induced bone loss, or cancer therapy-induced bone loss were not included. Older relevant studies were also included. Relevant presentations at large oncology congresses (eg, ASCO and ECCO/ESMO) during the last 5 years were included. However, smaller congresses and abstracts for congress presentations not readily available online were not included. Major limitations to these literature search methods are that some congress activity may have been missed and that relevant articles may not have been identified during the literature search.

\section{Role of antiresorptive agents in cancer therapy}

Bone remodeling occurs through the coordinated activity of bone formation and bone resorption. Bone metastases cause an imbalance in the activity of osteoclasts (boneresorbing cells) and osteoblasts (bone-forming cells), thereby weakening the skeleton and resulting in a vicious cycle of bone destruction and tumor growth facilitated by growth factors released during osteolysis. ${ }^{13}$ Therapies that inhibit osteoclast activity are used to prevent bone loss and delay skeletal-related events in patients with bone metastases from advanced cancer.

Antiresorptive therapies (ie, bisphosphonates and denosumab) are indicated for treating bone lesions and are effective for delaying onset of skeletal-related events (Table 1), ${ }^{4-7,9,10,14-25}$ and ameliorating bone pain. ${ }^{4-10}$ Bisphosphonates are a well established treatment option for maintaining bone health in patients with cancer and are a standard supplemental therapy for patients with advanced cancer. In the metastatic setting, the nitrogen-containing bisphosphonates, pamidronate and zoledronic acid, are approved for treating bone metastases from breast cancer. ${ }^{11,26}$ However, zoledronic acid (4 mg intravenously every 3 to 4 weeks) is the only bisphosphonate indicated for reducing the risk of skeletal-related events in patients with bone metastases from other solid tumors. Furthermore, zoledronic acid has a well established safety profile and a wealth of real-world data documenting tolerability and efficacy. Denosumab (120 mg subcutaneously every month) is a newer antiresorptive agent indicated for preventing skeletal-related events in patients with bone metastases from solid tumors but is not indicated for patients with multiple myeloma or hypercalcemia of malignancy. ${ }^{12}$

\section{Mechanisms of action of antiresorptive therapies Bisphosphonates}

All bisphosphonates accumulate in the mineral portion of the bone matrix and are released during bone resorption. 
Table I Key antiresorptive therapy clinical trials for prevention of skeletal-related events in advanced cancer

\begin{tabular}{|c|c|c|c|c|}
\hline Antiresorptive therapy & $\mathbf{N}$ & Dosing & Comparator & Results \\
\hline \multicolumn{5}{|l|}{ Prostate cancer } \\
\hline$Z \mathrm{~L}^{14}$ & $422^{\mathrm{a}}$ & $4 \mathrm{mg}$ IV q 3-4 wk & Placebo & $\begin{array}{l}\uparrow \text { Median time to Ist on-study SRE (not reached ZOL vs } \\
32 \text { I days placebo; } P=0.0 \mathrm{II} \text { ) } \\
\downarrow \text { In proportion of patients with SREs }(44.2 \% \text { ZOL vs } 33.2 \% \\
\text { placebo; } P=0.02 \mathrm{I})\end{array}$ \\
\hline $\mathrm{Dmab}^{4}$ & 1904 & $120 \mathrm{mg} \mathrm{SC} \mathrm{q} 4 \mathrm{wk}$ & ZOL 4 mg IV q 4 wk & $\begin{array}{l}\text { Additional I } 8 \% \uparrow \text { in time to Ist on-study SRE } \\
(P=0.008 ; \text { superiority })\end{array}$ \\
\hline \multicolumn{5}{|l|}{ Breast cancer } \\
\hline$Z \mathrm{~L}^{15}$ & 227 & $4 \mathrm{mg}$ IV q 3-4 wk & Placebo & $41 \% \downarrow$ in SRE risk $(P=0.019)^{\mathrm{b}} ; 13.5 \% \downarrow$ in fractures \\
\hline Dmab $^{9}$ & 2046 & $120 \mathrm{mg} \mathrm{SC}$ q $4 \mathrm{wk}$ & ZOL $4 \mathrm{mg}$ IV q 4 wk & Additional I8\% $\uparrow$ in time to Ist on-study SRE $(P=0.0 \mathrm{I})$ \\
\hline PAM $^{10}$ & 751 & $90 \mathrm{mg}$ IV q $3-4 \mathrm{wk}$ & Placebo & $\begin{array}{l}23 \% \downarrow \text { in SRE risk }(P<0.00 \mathrm{I})^{\mathrm{b}} ; 12 \% \downarrow \text { in pathologic } \\
\text { fractures }(P=0.002)\end{array}$ \\
\hline Ibandronate ${ }^{16}$ & 312 & $6 \mathrm{mg}$ IV q 3-4 wk & Placebo & $18 \% \downarrow$ in SRE risk $(P=0.03)^{\mathrm{b}} ; \downarrow \downarrow$ vertebral fractures $(P=0.023)$ \\
\hline Ibandronate ${ }^{17}$ & 564 & $50 \mathrm{mg} P O \mathrm{qd}$ & Placebo & $\begin{array}{l}\text { I } 4 \% \downarrow \text { in SRE risk }(P=0.08)^{\mathrm{b}} \text {; no significant difference } \\
\text { in number of fractures }\end{array}$ \\
\hline CLO'18-20 & 422 & 1600 mg PO qd & Placebo & $\begin{array}{l}31 \%, 17 \%, 8 \% \downarrow \text { in SRE risk respectively }(P=0.03, \text { pooled })^{\mathrm{b}} \text {; } \\
\uparrow \text { time to Ist fracture }(P=0.023)\left(\text { Kristensen et } \mathrm{al}^{18}\right), \\
\left.\downarrow \text { vertebral fractures }(P<0.025) \text { (Paterson et a }\left.\right|^{19}\right)\end{array}$ \\
\hline \multicolumn{5}{|l|}{$\begin{array}{l}\text { Other solid tumors or } \\
\text { multiple myeloma }\end{array}$} \\
\hline $\mathrm{ZOL}(\mathrm{BC} \text { or } \mathrm{MM})^{6,21}$ & $1116^{c}$ & $4 \mathrm{mg}$ IV q 3-4 wk & $\begin{array}{l}\text { PAM } 90 \mathrm{mg} \text { IV } \\
\text { q } 3-4 \mathrm{wk}\end{array}$ & $\begin{array}{l}\text { Additional } 20 \% \downarrow \text { in SRE risk }(P=0.025) ; 7 \% \downarrow \text { in pathologic } \\
\text { fractures }(P \leq 0.05)\end{array}$ \\
\hline ZOL $(\mathrm{OST})^{7,22}$ & $507^{\mathrm{a}}$ & $4 \mathrm{mg}$ IV q 3-4 wk & Placebo & $\begin{array}{l}\uparrow \text { Median time to Ist on-study SRE ( } 236 \text { days ZOL vs } \\
\text { I } 55 \text { days placebo; } P=0.01) ; 31 \% \downarrow \text { in SRE risk }(P=0.003)\end{array}$ \\
\hline ZOL (MM) $)^{23,24}$ & 1960 & $4 \mathrm{mg}$ IV q 3-4 wk & CLO $1600 \mathrm{mg} P O \mathrm{qd}$ & $\begin{array}{l}\downarrow \text { Proportion of patients with an SRE }(27.0 \% \text { ZOL vs } 35.3 \% \\
\text { CLO; } P=0.0004) \\
16 \% \downarrow \text { in mortality }(P=0.01 \text { I }), \uparrow \text { median OS } 5.5 \text { mo } \\
(P=0.04), 12 \% \uparrow \text { in PFS }(P=0.0179)\end{array}$ \\
\hline Dmab (OST or MM) ${ }^{5}$ & 1776 & $120 \mathrm{mg} \mathrm{SC} \mathrm{q} 4 \mathrm{wk}$ & ZOL $4 \mathrm{mg}$ IV q 4 wk & Additional $16 \% \uparrow$ in time to Ist on-study SRE $(P=0.0007)$ \\
\hline
\end{tabular}

Notes: ${ }^{a} \mathrm{n}$ reflects patients in the $4 \mathrm{mg} Z \mathrm{ZL}$ and placebo groups only; ${ }^{b}$ percentage decrease in SRE risk and $P$ value derived from the Cochrane database meta-analysis; ${ }^{25}$ 'n reflects patients in the $4 \mathrm{mg} Z \mathrm{ZOL}$ and $90 \mathrm{mg}$ PAM groups only.

Abbreviations: BC, breast cancer; CLO, clodronate; Dmab, denosumab; IV, intravenous; MM, multiple myeloma; OST, other solid tumors; OS, overall survival; PAM, pamidronate; PFS, progression-free survival; PO, orally; q, every; SC, subcutaneously; SRE, skeletal-related event; ZOL, zoledronic acid; wk, week; vs, versus.

The relative efficacy of bisphosphonates to delay the onset and reduce the risk of potentially debilitating skeletal-related events depends primarily on their chemical structure. Nonnitrogen-containing bisphosphonates, such as clodronate, are metabolized by osteoclasts into nonhydrolyzable cytotoxic ATP analogs. In contrast, nitrogen-containing bisphosphonates inhibit the mevalonate pathway after internalization by osteoclasts. ${ }^{27}$ Notably, zoledronic acid was the most potent bisphosphonate tested in preclinical model systems, with the greatest antiresorptive activity. ${ }^{28,29}$

All bisphosphonates are rapidly removed from the circulation by skeletal deposition or by renal filtration, after which they are excreted nonmetabolized within a few hours. The rate of bone turnover in a patient determines the proportion of bisphosphonates that becomes bound to the skeleton or is filtered through the kidneys. ${ }^{30}$ Patients with higher rates of bone turnover (eg, patients with metastatic bone disease or receiving therapies that increase bone turnover) retain more of the initial bisphosphonate dose within the skeleton compared with patients with lower rates of bone turnover (eg, healthy individuals). Furthermore, once bound to the skeleton, bisphosphonates are released during active bone remodeling, at which time they inhibit osteoclast function and viability. ${ }^{27,30}$ Therefore, bisphosphonates avidly bind the mineralized bone matrix and inhibit bone destruction in patients with bone metastases.

Originally considered supportive care, the role of nitrogen-containing bisphosphonates in therapy is evolving because of the growing body of evidence demonstrating their potential anticancer activity. Preclinical evidence supports the anticancer activity of bisphosphonates. ${ }^{31-33}$ Furthermore, numerous clinical studies examining the potential anticancer activity of bisphosphonates have been completed (Table 2), ${ }^{24,34-55}$ and several of them show that zoledronic acid influences the prevalence and persistence of disseminated tumor cells in bone. Indeed, one 
Table 2 Trials demonstrating anticancer benefits of bisphosphonates

\begin{tabular}{|c|c|c|c|c|}
\hline $\begin{array}{l}\text { Study } \\
\text { (follow-up) }\end{array}$ & $\mathbf{N}$ & Tumor type & BP & Results \\
\hline \multicolumn{5}{|l|}{ Neoadjuvant setting } \\
\hline Neoadjuvant AZURE ${ }^{34}$ & 205 & BC & ZOL $4 \mathrm{mg}$ IV q 3-4 wk for & $\downarrow$ RITS by $44 \%(27.4 \mathrm{~mm}$ vs $15.5 \mathrm{~mm} ; P=0.006)$ \\
\hline (6 mo) & & & 6 doses & $\uparrow p C R$ rate by nearly 2 -fold $(P=0.146)$ \\
\hline \multicolumn{5}{|l|}{ Adjuvant setting } \\
\hline Powles et $\mathrm{al}^{35}$ & 1069 & BC & CLO $1600 \mathrm{mg} / \mathrm{d}$ & $\uparrow \mathrm{BMFS}(\mathrm{HR}=0.692 ; P=0.043)$ \\
\hline$(5.6 y)$ & & & for $2 y$ & $\uparrow \mathrm{OS}(\mathrm{HR}=0.768 ; P=0.048)$ \\
\hline Diel et $\mathrm{al}^{36}$ & 302 & BC & CLO $1600 \mathrm{mg} / \mathrm{d}$ & $\uparrow$ BMFS $(92 \%$ vs $83 \% ; P=0.003)$ \\
\hline$(36 \mathrm{mo})$ & & & for $2 y$ & $\uparrow \mathrm{OS}(\mathrm{HR}=96 \%$ vs $85 \% ; P=0.000 \mathrm{I})$ \\
\hline$(8.5 y)^{37}$ & & & & $\uparrow$ OS $(79.6 \%$ vs $59.3 \% ; P=0.049)$ \\
\hline Saarto et al & 299 & BC & CLO 1600 mg/day & $\downarrow$ OS $(70 \%$ vs $83 \% ; P=0.009)$ \\
\hline$(5 y)^{38}$ & & & for $3 y$ & $\downarrow$ DFS ( $56 \%$ vs $71 \% ; P=0.007)$ \\
\hline$(10 y)^{39}$ & & & & $\downarrow$ DFS (45\% vs $58 \% ; P=0.01)$; Similar OS \\
\hline NSABP- $34^{40}$ & 3323 & BC & CLO $1600 \mathrm{mg} / \mathrm{d}$ & No effect on DFS $(\mathrm{HR}=0.91 ; P=0.27)$ \\
\hline \multirow[t]{2}{*}{$(8.4 y)$} & & & for $3 \mathrm{yr}$ & $\uparrow \mathrm{BMFI}(\mathrm{HR}=0.63 ; P=0.024)$ and $\uparrow \mathrm{NBMFI}$ \\
\hline & & & & $(H R=0.63 ; P=0.015)$ in women $\geq 50 y$ \\
\hline GAIN $^{41}$ & 3023 & BC & IBN $50 \mathrm{mg} / \mathrm{d}$ for 2 y & No effect on DFS $(H R=0.945 ; P=0.59)$ or OS \\
\hline (39 mo) & & & & $(H R=1.04 ; P=0.80)$ \\
\hline Lin et $\mathrm{al}^{42}$ & 45 & BC & ZOL 4 mg IV monthly & $\downarrow$ In persistent DTCs: \\
\hline \multirow[t]{2}{*}{ (24 mo) } & & & for $2 y$ & $\downarrow \ln 66 \%$ of patients at I y $(P=0.0018)$ \\
\hline & & & & $\downarrow \ln 7 \mathrm{I} \%$ of patients at 2 y $(P=0.0 \mathrm{I})$ \\
\hline Solomayer et $\mathrm{a}^{43}$ & 76 & BC & ZOL 4 mg IV q 4 wk & $\downarrow$ In persistent DTCs $(P=0.066)$ \\
\hline (12 mo) & & & for $2 y$ & $\uparrow$ DTC-free patients (67\% vs $35 \% ; P=0.009$ ) \\
\hline Aft et $\mathrm{al}^{44}$ & 120 & BC & ZOL $4 \mathrm{mg}$ IV q 3 wk & $\downarrow$ In persistent DTCs ( $30 \%$ vs $47 \% ; P=0.054)$ \\
\hline$(3 \mathrm{mo})$ & & & for I y & \\
\hline Rack et a ${ }^{45}$ & 172 & BC & ZOL 4 mg IV q 4 wk & $\downarrow$ Proportion with persistent DTCs after ZOL \\
\hline$(39 \mathrm{mo})$ & & & for $6 \mathrm{mo}$ & $(13 \%$ vs $27 \% ; P=0.099)$ \\
\hline ZO-FAST & 1065 & $\mathrm{BC}^{\mathrm{a}}$ & ZOL 4 mg IV q 6 mo for 5 y; & $\uparrow \mathrm{DFS}(\mathrm{HR}=0.588 ; P=0.03 \mid 4)$ with immediate \\
\hline$(36 \mathrm{mo})^{46}$ & & & immediate vs delayed & vs delayed ZOL \\
\hline$(60 \mathrm{mo})^{47}$ & & & & $\uparrow \mathrm{DFS}(\mathrm{HR}=0.66 ; P=0.0375)$ \\
\hline ABCSG- 12 & 1803 & $\mathrm{BC}^{\mathrm{b}}$ & ZOL 4 mg IV & $\uparrow \mathrm{DFS}(\mathrm{HR}=0.64 ; P=0.01)$ \\
\hline$(48 \mathrm{mo})^{48}$ & & & q 6 mo for $3 y$ & \\
\hline \multirow[t]{2}{*}{$(84 \mathrm{mo})^{49}$} & & & & $\uparrow \mathrm{DFS}(\mathrm{HR}=0.72 ; P=0.014)$ \\
\hline & & & & $\uparrow \mathrm{OS}(\mathrm{HR}=0.63 ; P=0.049)$ \\
\hline & 3360 & BC & ZOL 4 mg IV & No change in DFS in overall population \\
\hline \multirow[t]{5}{*}{$(59 \mathrm{mo})^{50}$} & & & q 3-4 wk $\times 6$ & $(H R=0.98 ; P=0.79)$ \\
\hline & & & $4 \mathrm{mg} \mathrm{q} 3 \mathrm{mo} \times 8$ & Trend $\uparrow$ OS in the overall population \\
\hline & & & $4 \mathrm{mg} \mathrm{q} 6 \mathrm{mo} \times 5$ & $(H R=0.85 ; P=0.07)$ \\
\hline & & & & $\uparrow$ IDFS $(\mathrm{HR}=0.75 ; P=0.02)$ and $\uparrow \mathrm{OS}(\mathrm{HR}=0.74$ \\
\hline & & & & $P=0.04)$ in women $>5$ y postmenopause $(n=104 I)$ \\
\hline \multicolumn{5}{|l|}{ Metastatic setting } \\
\hline Mystakidou et $\mathrm{al}^{51}$ & 40 & Advanced solid & ZOL 4 mg IV monthly & $\uparrow \mathrm{BMFS}$ at $12 \mathrm{mo}(60 \%$ vs $10 \% ; P<0.0005)$ \\
\hline$(18 \mathrm{mo})$ & & tumors (no BM) & & $\uparrow \mathrm{BMFS}$ at $18 \mathrm{mo}(20 \%$ vs $5 \% ; P=0.0002)$ \\
\hline Zaghloul et al ${ }^{52}$ & 40 & Bladder cancer & ZOL 4 mg IV monthly & $\uparrow 1-y$ OS $(36.3 \%$ vs $0 \% ; P=0.004)$ \\
\hline$(24 w k)$ & & & for 6 mo & \\
\hline Zarogoulidis et $\mathrm{al}^{53}$ & 144 & LC & ZOL $4 \mathrm{mg}$ IV q 2 I d & $\uparrow$ OS by $>6$ mo $(578 \mathrm{~d}$ vs $384 \mathrm{~d} ; P<0.00 \mathrm{I})$ \\
\hline Aviles et a ${ }^{54}$ & 94 & MM & ZOL $4 \mathrm{mg}$ IV q $28 \mathrm{~d}$ & $\uparrow 5$-y OS $(80 \%$ vs $46 \% ; P<0.01)$ \\
\hline$(49.6 \mathrm{mo})$ & & & & $\uparrow 5$-y EFS $(80 \%$ vs $52 \% ; P<0.01)$ \\
\hline MRC Myeloma IX'24 & 1960 & MM & ZOL 4 mg IV q 3-4 wk & $\uparrow \mathrm{PFS}(\mathrm{HR}=0.883 ; P=0.0179)$ \\
\hline$(3.7 y)$ & & & & $\uparrow \mathrm{OS}(\mathrm{HR}=0.842 ; P=0.0118)$ \\
\hline
\end{tabular}

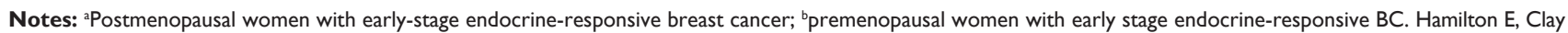
TM, Blackwell KL. New perspectives on zoledronic acid in breast cancer: potential augmentation of anticancer immune response. Cancer Invest. 20I I;29(8):533-54I. Copyright 20I I, Informa Healthcare. Reproduced with permission of Informa Healthcare. ${ }^{55}$

Abbreviations: BC, breast cancer; BMFI, bone metastasis-free interval; BMFS, bone metastasis-free survival; DFS, disease-free survival; DTC, disseminated tumor cell; EFS, eventfree survival; HR, hazard ratio; IBN, ibandronate; I IDFS, invasive disease-free survival; IV, intravenous; LC, lung cancer; MM, multiple myeloma; NBMFI, nonbone metastasis-free interval; OS, overall survival; pCR, pathologic complete response; PFS, progression-free survival; q, every; RITS, residual invasive tumor size; ZOL, zoledronic acid.

possible mechanism of nitrogen-containing bisphosphonate anticancer activity may be through rendering the bone marrow microenvironment less suitable for the growth of tumor cells. Some bisphosphonates may also target some steps involved in the metastatic process, including tumor cell growth, migration, adhesion to extracellular matrix, extravasation into distant tissues, angiogenesis, and avoidance of immune surveillance. Furthermore, nitrogen-containing 
bisphosphonates have demonstrated synergistic anticancer activity when used in combination with anticancer agents in the preclinical setting, and clinical studies to explore this effect further are ongoing. Knowledge and understanding of the potential anticancer effects of bisphosphonates could influence a patient's preference for one antiresorptive therapy over another.

\section{Denosumab}

Denosumab is a new antiresorptive therapeutic option for patients with bone metastases from solid tumors, but not for patients with multiple myeloma. ${ }^{12}$ It is a fully human monoclonal antibody that specifically targets the receptor activator of nuclear factor kappa B ligand (RANKL), a key modulator of osteoclast-mediated bone resorption. Notably, in head-tohead clinical trials, denosumab was found to be superior to zoledronic acid for delaying skeletal-related events in patients with bone metastases from breast or prostate cancer and noninferior to zoledronic acid for delaying SREs in patients with bone metastases from other solid tumors. ${ }^{4,5,9}$ Denosumab is not incorporated into the mineralized bone matrix and does not selectively target bone. ${ }^{56,57}$ Because RANKL is expressed systemically, blocking RANKL with denosumab may interfere with RANKL-mediated pathways outside of bone. Indeed, in addition to osteoclasts, RANKL is also expressed by cells of the immune system (eg, T cells, B cells, and dendritic cells), vascular endothelial cells, heart, brain, kidney, skeletal muscle, and skin. ${ }^{58-60}$ Functions of RANKL in these cells include regulation of vascular integrity, lymph node organization, $\mathrm{T}$ cell and dendritic cell communication, and dendritic cell survival. Furthermore, in murine models, RANKL mRNA and protein have been detected throughout development, suggesting multiple other potential functions of the protein. ${ }^{61}$

Serum steady-state levels of denosumab are reached around 6 months after $120 \mathrm{mg}$ dosing every 4 weeks, and the mean serum elimination half-life is 28 days. ${ }^{12}$ Denosumab clearance is proportional to body weight, with steady-state exposure higher in lower weight individuals compared with higher weight individuals. ${ }^{12}$ Although denosumab remains in serum for several weeks, studies suggest that regular dosing is required to maintain its antiresorptive effects. ${ }^{30,62,63}$ Indeed, studies in patients with osteoporosis showed that the bone turnover marker levels increased above baseline levels within 3-6 months after discontinuation. ${ }^{62,63}$ Furthermore, denosumab discontinuation was associated with decreased bone mineral density at the lumbar spine (6.6\%) and total hip (5.3\%) within 12 months of receiving the final dose. ${ }^{63}$ These studies suggest that stopping denosumab therapy may be associated with a rebound effect, leading to subsequent decrease in bone mineral density. ${ }^{30,62,63}$ It is important for clinicians to understand these issues when prescribing denosumab so that they can stress the importance of remaining on therapy. In addition, the rebound effect is of particular relevance in a real world setting as patients with advanced cancer are likely to experience events that may warrant discontinuation of therapy, thereby increasing their risk of skeletal-related events.

Denosumab is newly approved in the US for use in patients with bone metastases from solid tumors. Although a 2-year open-label extension of the skeletal-related events study in patients with breast cancer confirmed the safety profile of denosumab established in the primary study, ${ }^{64}$ it has not been reported how the efficacy and safety of denosumab therapy in clinical trials will translate to longterm use in clinical practice. No clinical anticancer effects of denosumab have been reported; however, a Phase III study in patients with nonmetastatic castration-resistant prostate cancer showed that it significantly increased bone metastasis-free survival by a median of 4.2 months versus placebo (hazard ratio $[\mathrm{HR}]=0.85 ; P=0.028$ ). Despite this statistically significant finding, denosumab had no effect on overall disease progression $(\mathrm{HR}=0.90 ; P=0.13)$ or survival (HR $=1.01 ; P=0.91)$. Moreover, this study reported a higher incidence of osteonecrosis of the jaw with denosumab compared with other denosumab trials in patients with advanced cancer (5\% versus $2 \%) .{ }^{65,66}$ Ongoing anticancer trials with denosumab include ABCSG-18 ( $n=3400)$ and D-CARE $(n=4500)$, both in patients with breast cancer. ${ }^{67,68}$

\section{Safety and managing adverse events with antiresorptive therapies Acute-phase responses}

Acute-phase responses have been reported in patients receiving antiresorptive therapy and consist of flu-like symptoms including fever, chills, flushing, bone pain and/or arthralgias, and myalgias. Approximately $15 \%-27 \%$ of patients with advanced cancer receiving nitrogen-containing bisphosphonate therapy have reported APR-related adverse events. ${ }^{4,5,9}$ An integrated analysis of the three Phase III clinical trials for treating bone metastases in patients with advanced cancer shows that APR-related adverse events were reported less frequently with denosumab compared with zoledronic acid ( $9 \%$ versus $20 \%$, respectively). ${ }^{65}$

It should be noted that APR-related adverse events are often easily managed, ${ }^{69}$ and prophylactic use of acetaminophen or diphenhydramine before the first bisphosphonate dose can 
reduce the incidence and severity of these events. ${ }^{70}$ Furthermore, APR-related adverse events are usually mild and reversible. ${ }^{71}$ These events either do not manifest in subsequent cycles of nitrogen-containing bisphosphonate therapy or are of reduced severity. Therefore, APR-related adverse events need not be a contraindication to the long-term use of bisphosphonate therapy. The primary care physician must be aware of how to manage APR-related adverse events and should communicate this information to patients with cancer.

\section{Osteonecrosis of the jaw}

Osteonecrosis of the jaw is an uncommon but potentially serious adverse event of complex etiology, generally affecting $1 \%-2 \%$ of patients with advanced cancer receiving complex treatment regimens including chemotherapy and antiresorptive therapy (ie, nitrogen-containing bisphosphonates and denosumab). ${ }^{4,5,9,65} \mathrm{~A}$ combined analysis of the three Phase III trials comparing denosumab with zoledronic acid in patients with bone metastases confirms these rates of osteonecrosis of the jaw and showed that, as of October 2010 , osteonecrosis of the jaw resolved in $36 \%$ of patients (40\% for denosumab versus $30 \%$ for zoledronic acid). ${ }^{72}$ In contrast with the metastatic setting, the risk of osteonecrosis of the jaw with antiresorptive therapy (zoledronic acid or denosumab) in the adjuvant setting is extremely rare. $^{48,73,74}$ The infrequent dosing schedule for zoledronic acid or denosumab might be one factor contributing to the exceptionally low event rate for osteonecrosis of the jaw in this setting.
Despite the potential seriousness of this adverse event in the metastatic setting, the risk of developing osteonecrosis of the jaw can be minimized by preventive dental care before initiating bisphosphonate therapy. ${ }^{75}$ The primary care physician can play a critical role in educating the patient on the importance of preventive dental care in this setting. Furthermore, conservative management often leads to resolution of osteonecrosis of the jaw ${ }^{76}$ (Table 3 ). ${ }^{77}$ Although not specifically examined with denosumab, these preventive techniques also would likely be useful for minimizing the risk of osteonecrosis of the jaw in patients receiving denosumab.

\section{Renal impairment}

The incidence of renal impairment is high in elderly patients (ie, age $\geq 65$ years) even in the absence of comorbidities. ${ }^{78-81}$ Renal impairment is also common among patients with cancer. ${ }^{82}$ Moreover, this patient population often has preexisting comorbidities or other risk factors that increase the risk of renal impairment. For example, patient age, pre-existing kidney disease, chronic comorbidities such as diabetes, hypertension, and cardiac insufficiency, and some long-term medications all increase the risk of renal impairment. ${ }^{83}$ Thus, monitoring renal function in patients with cancer is crucial for safe administration of anticancer agents and antiresorptive therapies, which can be nephrotoxic. ${ }^{84,85}$ Primary care providers can play a critical role in managing comorbidities and multiple medications.

For patients receiving nitrogen-containing bisphosphonates, monitoring renal function (ie, serum creatinine

Table 3 American Association of Oral and Maxillofacial Surgeons recommendations for treatment of osteonecrosis of the jaw

\begin{tabular}{|c|c|c|}
\hline Stage & Symptoms & Recommended treatment \\
\hline At risk & $\begin{array}{l}\text { No apparent necrotic bone in patients who have been treated with either } \\
\text { oral or intravenous bisphosphonates }\end{array}$ & $\begin{array}{l}\text { - No treatment indicated } \\
\text { - Patient education }\end{array}$ \\
\hline 0 & $\begin{array}{l}\text { No clinical evidence of necrotic bone, but nonspecific clinical findings } \\
\text { and symptoms }\end{array}$ & $\begin{array}{l}\text { - Systemic management, including the } \\
\text { use of pain medication and antibiotics }\end{array}$ \\
\hline I & $\begin{array}{l}\text { Exposed/necrotic bone in patients who are asymptomatic and have } \\
\text { no evidence of infection }\end{array}$ & $\begin{array}{l}\text { - Antibacterial mouth rinse } \\
\text { - Quarterly clinical follow-up } \\
\text { - Patient education }\end{array}$ \\
\hline 2 & $\begin{array}{l}\text { Exposed/necrotic bone associated with infection } \\
\text { (ie, pain and erythema in the region of exposed bone) }\end{array}$ & $\begin{array}{l}\text { - Symptomatic treatment with } \\
\text { broad-spectrum antibiotics } \\
\text { - Antibacterial mouth rinse } \\
\text { - Pain control } \\
\text { - Superficial debridements } \\
\text { to relieve soft tissue irritation }\end{array}$ \\
\hline 3 & $\begin{array}{l}\text { Stage } 2 \text { symptoms + I or more of the following: exposed and necrotic bone } \\
\text { extending beyond the region of alveolar bone (ie, inferior border and ramus } \\
\text { in the mandible, maxillary sinus and zygoma in the maxilla) resulting in } \\
\text { pathologic fracture, extraoral fistula, oral antral/oral nasal communication, } \\
\text { or osteolysis extending to the inferior border of the mandible or sinus floor }\end{array}$ & $\begin{array}{l}\text { - Antibacterial mouth rinse } \\
\text { - Antibiotic therapy and pain control } \\
\text { - Surgical debridement/resection } \\
\text { for longer-term palliation }\end{array}$ \\
\hline
\end{tabular}

Note: Adapted from Ruggiero SL, Dodson TB, Assael LA, Landesberg R, Marx RE, Mehrotra B. American Association of Oral and Maxillofacial Surgeons. Position paper on bisphosphonate-related osteonecrosis of the jaw - 2009 update. Aust Endod J. 2009;35:1 19-130. Copyright 2009, with permission from Elsevier. ${ }^{77}$ 
assessment before each dose) is required because nitrogencontaining bisphosphonates not bound to the skeleton are cleared by renal filtration. Dose adjustment guidelines for nitrogen-containing bisphosphonates are available for patients with renal impairment (Table 4). ${ }^{11,26,69,86-88}$ Monitoring renal function with denosumab is not required. ${ }^{12}$ However, the rate of renal adverse events was similar for zoledronic acid compared with denosumab in patients with castration-resistant prostate cancer. ${ }^{4}$ Moreover, an integrated analysis of the trials comparing zoledronic acid with denosumab for the treatment of bone metastasis also showed similar rates of renal adverse events (12\% versus $9 \%$, respectively). ${ }^{65}$ It should also be noted that patients with renal impairment who receive denosumab are at increased risk of developing hypocalcemia, a potentially serious complication. Indeed, $10 \%$ of patients receiving denosumab experienced hypocalcemia compared with $5 \%$ of patients receiving zoledronic acid. ${ }^{65}$ Therefore, it is prudent to assess renal function regularly in patients with cancer receiving antiresorptive therapy.

When determining the optimal choice of antiresorptive therapy for an individual patient, the safety profiles of antiresorptive therapies need to be considered within the context of individual clinical situations and preferences. Other tools that can be useful for evaluating the risk/benefit ratios of a therapy are number-needed-to-treat (NNT) and cost/benefit analyses. The NNT is a measure used to compare the relative efficacies of two therapies. It represents the number of patients who need to be treated with an agent to avoid one additional event. In addition to NNT analyses, cost/benefit analyses can help evaluate the cost-effectiveness of a therapy given the known efficacy and safety profiles.

Table 4 Modified bisphosphonate dosing schedules for renal impairment

\begin{tabular}{|c|c|c|c|}
\hline \multirow{2}{*}{$\begin{array}{l}\text { Creatinine } \\
\text { clearance, } \\
\mathrm{mL} / \mathrm{min}\end{array}$} & \multicolumn{3}{|c|}{ Dose adjustment } \\
\hline & $\begin{array}{l}\text { Pamidronate, } \\
\text { mg }^{\mathrm{a}}\end{array}$ & $\begin{array}{l}\text { Zoledronic } \\
\text { acid, } \text { mg }^{\mathbf{b}}\end{array}$ & $\begin{array}{l}\text { Ibandronate, } \\
\text { mgc }^{\mathrm{c}}\end{array}$ \\
\hline $90-60$ & $60-90$ & 4 & 6 \\
\hline $60-50$ & $60-90$ & 3.5 & 6 \\
\hline $50-40$ & $60-90$ & 3.3 & 4 \\
\hline $40-30$ & $60-90$ & 3.0 & 4 \\
\hline $\begin{array}{l}<30 \text { or patients } \\
\text { receiving } \\
\text { hemodialysis }\end{array}$ & $\begin{array}{l}\text { Not } \\
\text { recommended }\end{array}$ & $\begin{array}{l}\text { Not } \\
\text { recommended }\end{array}$ & $\begin{array}{l}2 \text { or not } \\
\text { recommended }\end{array}$ \\
\hline \multicolumn{4}{|c|}{ 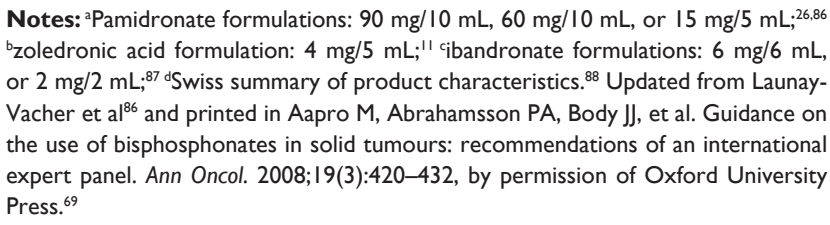 } \\
\hline
\end{tabular}

\section{NNT and cost/benefit analyses for zoledronic acid versus denosumab}

The NNT analysis can be used to make sense of numerical results from clinical trials, and is useful in evaluating the real-world clinical benefit of one agent relative to another. Recently, NNT analyses were performed using skeletalrelated event data from two Phase III clinical trials comparing denosumab with zoledronic acid for treating bone metastases in patients with castration-resistant prostate cancer or other solid tumors (excluding breast cancer). ${ }^{89}$ These analyses determined the NNT required to avoid a single skeletalrelated event during continuous, long-term denosumab therapy in patients with castration-resistant prostate cancer or other solid tumors. For patients with castration-resistant prostate cancer, 22 patients would need to be treated with denosumab for 41 months to prevent any skeletal-related event versus zoledronic acid. ${ }^{89}$ Similarly, in patients with other solid tumors, 21 patients would need to be treated with denosumab for 34 months to prevent any one skeletalrelated event compared with zoledronic acid. ${ }^{89}$ Furthermore, the NNT required to prevent radiation to bone, fractures, or surgery to bone was notably high for patients with castrationresistant prostate cancer $(37,163$, and 317 , respectively) or other solid tumors $\left(36,56\right.$, and 167 , respectively) ${ }^{89}$ These analyses show that the potential incremental benefit of denosumab compared with zoledronic acid for preventing any one skeletal-related event would be realized only after 21-22 patients received long-term (34-41 months) denosumab therapy. Moreover, the higher NNTs for more debilitating and costly skeletal-related events (eg, fracture, surgery to bone) suggest a low incremental benefit with denosumab compared with zoledronic acid. Indeed, these marginal benefits need to be considered in conjunction with the safety profiles and costs of denosumab and zoledronic acid when choosing an antiresorptive therapy for patients with metastatic bone disease from advanced cancer.

In addition to the safety and efficacy of antiresorptive therapies, cost also must be taken into consideration, because drug costs will influence the out-of-pocket expenses incurred by patients. Cost/benefit analyses can be useful for evaluating the cost, efficacy, and safety considerations of a therapy. Such analyses utilizing a literature-based Markov model of denosumab compared with zoledronic acid were based on data from 27 months of therapy in Phase III clinical trials in patients with bone metastases from castration-resistant prostate cancer or breast cancer. These analyses show that denosumab is not cost-effective compared with zoledronic acid. ${ }^{90,91}$ Indeed, the cost per quality-adjusted life-year (QALY) for patients with 
breast cancer is approximately $\$ 697,000,{ }^{91}$ and the cost per QALY for patients with castration-resistant prostate cancer is approximately $\$ 1.25$ million. ${ }^{90}$ Both of these figures are far above what is considered a good medical value in the US (ie, $\$ 50,000$ to $\$ 100,000$ per QALY). ${ }^{90,91}$ In both analyses, the high cost per QALY with denosumab is due to higher drug acquisition costs, combined with the limited improvement in prevention of skeletal-related events with denosumab versus zoledronic acid. These high costs per QALY for denosumab suggest that the cost/benefit ratio of denosumab may be prohibitive for many patients. However, a third analysis using a literature-based lifetime Markov model showed smaller values for the increase costs per QALY gained with denosumab ( $\$ 78,915$ for breast cancer, $\$ 49,405$ for castration-resistant prostate cancer, and $\$ 67,931$ for non-small-cell lung cancer). ${ }^{92}$ The increased cost per QALY gained with denosumab compared with zoledronic acid in this analysis is within what is considered good medical value in the US. Overall, the costeffectiveness of denosumab remains open to interpretation at this time, and may influence treatment decisions differently in each geographic area/practice setting.

\section{Conclusion}

Clinical data indicate that the antiresorptive therapies, zoledronic acid and denosumab, are generally well tolerated in patients with bone metastases from advanced cancer. It should be noted that bisphosphonates are a well established treatment option with a long history of clinical use in this patient population and have a well characterized and manageable safety profile. Denosumab is a newly approved antiresorptive therapy option for patients with bone metastases from solid tumors. Although the long-term safety profile of denosumab in clinical practice remains to be determined, it provides an alternative antiresorptive therapy option for this patient population. However, cost/benefit analyses do not favor denosumab over zoledronic acid for treating bone metastases from solid tumors.

Patient compliance with antiresorptive therapy is critical for maintaining bone health and quality of life. Understanding the benefits of antiresorptive therapies and the risks associated with skeletal-related events may improve patient compliance. Because primary care physicians generally have more contact with their patients than oncologists, they are in an excellent position to monitor compliance and help educate patients on the benefits and risks of various antiresorptive therapies. Therefore, primary care physicians need to be aware of the risks and benefits of various antiresorptive therapy options for patients with advanced cancer.

\section{Acknowledgment}

I would like to thank Christy A Russell for her critical review of the manuscript and insightful comments.

\section{Disclosure}

Financial support for medical editorial assistance was provided by Novartis Pharmaceuticals. I thank Duprane Pedaci Young, ProEd Communications, Inc., for medical editorial assistance with this manuscript.

\section{References}

1. Coleman RE. Metastatic bone disease: clinical features, pathophysiology and treatment strategies. Cancer Treat Rev. 2001; 27(3):165-176.

2. Saad F. New research findings on zoledronic acid: survival, pain, and anti-tumor effects. Cancer Treat Rev. 2008;34(2):183-192.

3. Weinfurt KP, Li Y, Castel LD, et al. The significance of skeletal-related events for the health-related quality of life of patients with metastatic prostate cancer. Ann Oncol. 2005;16(4):579-584.

4. Fizazi K, Carducci M, Smith M, et al. Denosumab versus zoledronic acid for treatment of bone metastases in men with castration-resistant prostate cancer: a randomised, double-blind study. Lancet. 2011; 377(9768):813-822.

5. Henry DH, Costa L, Goldwasser F, et al. Randomized, double-blind study of denosumab versus zoledronic acid in the treatment of bone metastases in patients with advanced cancer (excluding breast and prostate cancer) or multiple myeloma. J Clin Oncol. 2011;29(9):1125-1132.

6. Rosen LS, Gordon D, Kaminski M, et al. Long-term efficacy and safety of zoledronic acid compared with pamidronate disodium in the treatment of skeletal complications in patients with advanced multiple myeloma or breast carcinoma: a randomized, double-blind, multicenter, comparative trial. Cancer. 2003;98(8):1735-1744.

7. Rosen LS, Gordon D, Tchekmedyian NS, et al. Long-term efficacy and safety of zoledronic acid in the treatment of skeletal metastases in patients with nonsmall cell lung carcinoma and other solid tumors: a randomized, Phase III, double-blind, placebo-controlled trial. Cancer. 2004;100(12):2613-2621.

8. Saad F, Gleason DM, Murray R, et al. Long-term efficacy of zoledronic acid for the prevention of skeletal complications in patients with metastatic hormone-refractory prostate cancer. $J$ Natl Cancer Inst. 2004;96(11):879-882.

9. Stopeck AT, Lipton A, Body JJ, et al. Denosumab compared with zoledronic acid for the treatment of bone metastases in patients with advanced breast cancer: a randomized, double-blind study. J Clin Oncol. 2010;28(35):5132-5139.

10. Lipton A, Theriault RL, Hortobagyi GN, et al. Pamidronate prevents skeletal complications and is effective palliative treatment in women with breast carcinoma and osteolytic bone metastases: long term follow-up of two randomized, placebo-controlled trials. Cancer. 2000;88(5):1082-1090.

11. Zometa ${ }^{\circledR}$ [prescribing information]. East Hanover, NJ: Novartis Pharmaceuticals Corporation; 2011.

12. $\mathrm{Xgeva}^{\circledR}$ [prescribing information]. Thousand Oaks, CA: Amgen Inc; 2010 .

13. Mundy GR. Metastasis to bone: causes, consequences and therapeutic opportunities. Nat Rev Cancer. 2002;2(8):584-593.

14. Saad F, Gleason DM, Murray R, et al. A randomized, placebo-controlled trial of zoledronic acid in patients with hormone-refractory metastatic prostate carcinoma. J Natl Cancer Inst. 2002;94(19): 1458-1468.

15. Kohno N, Aogi K, Minami H, et al. Zoledronic acid significantly reduces skeletal complications compared with placebo in Japanese women with bone metastases from breast cancer: a randomized, placebo-controlled trial. J Clin Oncol. 2005;23(15):3314-3321. 
16. Body JJ, Diel IJ, Lichinitser MR, et al. Intravenous ibandronate reduces the incidence of skeletal complications in patients with breast cancer and bone metastases. Ann Oncol. 2003;14(9):1399-1405.

17. Body JJ, Diel IJ, Lichinitzer M, et al. Oral ibandronate reduces the risk of skeletal complications in breast cancer patients with metastatic bone disease: results from two randomised, placebo-controlled Phase III studies. Br J Cancer. 2004;90(6):1133-1137.

18. Kristensen B, Ejlertsen B, Groenvold M, Hein S, Loft H, Mouridsen HT. Oral clodronate in breast cancer patients with bone metastases: a randomized study. J Intern Med. 1999;246(1):67-74.

19. Paterson AH, Powles TJ, Kanis JA, McCloskey E, Hanson J, Ashley S. Double-blind controlled trial of oral clodronate in patients with bone metastases from breast cancer. J Clin Oncol. 1993;11(1): 59-65.

20. Tubiana-Hulin M, Beuzeboc P, Mauriac L, et al. Double-blinded controlled study comparing clodronate versus placebo in patients with breast cancer bone metastases. Bull Cancer. 2001;88(7):701-707. French.

21. Rosen LS, Gordon D, Kaminski M, et al. Zoledronic acid versus pamidronate in the treatment of skeletal metastases in patients with breast cancer or osteolytic lesions of multiple myeloma: a phase III, double-blind, comparative trial. Cancer J. 2001;7(5):377-387.

22. Rosen LS, Gordon D, Tchekmedyian S, et al. Zoledronic acid versus placebo in the treatment of skeletal metastases in patients with lung cancer and other solid tumors: a phase III, double-blind, randomized trial - the Zoledronic Acid Lung Cancer and Other Solid Tumors Study Group. J Clin Oncol. 2003;21(16):3150-3157.

23. Morgan GJ, Davies F, Gregory W, et al. Zoledronic acid prolongs time to first skeletal-related event, progression-free survival, and overall survival versus clodronate in newly diagnosed multiple myeloma: MRC Myeloma IX trial results. Abstract 0562 presented at the 15th Congress of the European Hematology Association, June 10-13, 2010, Barcelona, Spain.

24. Morgan GJ, Davies FE, Gregory WM, et al. First-line treatment with zoledronic acid as compared with clodronic acid in multiple myeloma (MRC Myeloma IX): a randomised controlled trial. Lancet. 2010; 376(9757):1989-1999.

25. Pavlakis N, Schmidt R, Stockler M. Bisphosphonates for breast cancer. Cochrane Database Syst Rev. 2005;3:CD003474.

26. Aredia ${ }^{\circledR}$ [prescribing information]. East Hanover, NJ: Novartis Pharmaceuticals Corporation; 2011.

27. Rogers MJ, Gordon S, Benford HL, et al. Cellular and molecular mechanisms of action of bisphosphonates. Cancer. 2000;88(Suppl 12): 2961-2978.

28. Dunford JE, Thompson K, Coxon FP, et al. Structure-activity relationships for inhibition of farnesyl diphosphate synthase in vitro and inhibition of bone resorption in vivo by nitrogen-containing bisphosphonates. J Pharmacol Exp Ther. 2001;296(2):235-242.

29. Green JR, Muller K, Jaeggi KA. Preclinical pharmacology of CGP 42'446, a new, potent, heterocyclic bisphosphonate compound. J Bone Miner Res. 1994;9(5):745-751.

30. Hadji P. Clinical considerations for the use of antiresorptive agents in the treatment of metastatic bone disease. Crit Rev Oncol Hematol. 2011;80(2):301-313.

31. Green JR, Guenther A. The backbone of progress - preclinical studies and innovations with zoledronic acid. Crit Rev Oncol Hematol. 2011;77 Suppl 1:S3-S12.

32. Neville-Webbe HL, Gnant M, Coleman RE. Potential anticancer properties of bisphosphonates. Semin Oncol. 2010;37 Suppl 1:S53-S65.

33. Winter MC, Holen I, Coleman RE. Exploring the anti-tumour activity of bisphosphonates in early breast cancer. Cancer Treat Rev. 2008;34(5): 453-475.

34. Coleman RE, Winter MC, Cameron D, et al. The effects of adding zoledronic acid to neoadjuvant chemotherapy on tumour response: exploratory evidence for direct anti-tumour activity in breast cancer. Br J Cancer. 2010;102(7):1099-1105.
35. Powles T, Paterson A, McCloskey E, et al. Reduction in bone relapse and improved survival with oral clodronate for adjuvant treatment of operable breast cancer [ISRCTN83688026]. Breast Cancer Res. 2006;8(2):R13.

36. Diel IJ, Solomayer EF, Costa SD, et al. Reduction in new metastases in breast cancer with adjuvant clodronate treatment. $N$ Engl J Med. 1998;339(6):357-363.

37. Diel IJ, Jaschke A, Solomayer EF, et al. Adjuvant oral clodronate improves the overall survival of primary breast cancer patients with micrometastases to the bone marrow: a long-term follow-up. Ann Oncol. 2008;19(12):2007-2011.

38. Saarto T, Blomqvist C, Virkkunen P, Elomaa I. Adjuvant clodronate treatment does not reduce the frequency of skeletal metastases in nodepositive breast cancer patients: 5-year results of a randomized controlled trial. J Clin Oncol. 2001;19(1):10-17.

39. Saarto T, Vehmanen L, Virkkunen P, Blomqvist C. Ten-year follow-up of a randomized controlled trial of adjuvant clodronate treatment in nodepositive breast cancer patients. Acta Oncol. 2004;43(7):650-656.

40. Paterson AHG, Anderson SJ, Lembersky BC, et al. NSABP protocol B-34: a clinical trial comparing adjuvant clodronate vs placebo in early stage breast cancer patients receiving systemic chemotherapy and/or tamoxifen or no therapy - final analysis. Abstract S2-3 presented at the CTRC-AACR San Antonio Breast Cancer Symposium, December 6-10, 2011, San Antonio, TX.

41. Mobus V, Diel IJ, Harbeck N, et al. GAIN (German Adjuvant Intergroup Node Positive) study: a phase-III multicenter trial to compare dose dense, dose intense ETC (iddETC) vs EC-TX and ibandronate vs observation in patients with node-positive primary breast cancer - 1 st interim EFFICACY analysis. Abstract S2-4 presented at the CTRCAACR San Antonio Breast Cancer Symposium, December 6-10, 2011, San Antonio, TX.

42. Lin AY, Park JW, Scott J, et al. Zoledronic acid as adjuvant therapy for women with early stage breast cancer and disseminated tumor cells in bone marrow. J Clin Oncol. 2008;26(Suppl 15):20s. Abstract 559.

43. Solomayer EF, Gebauer G, Hirnle P, et al. Influence of zoledronic acid on disseminated tumor cells (DTC) in primary breast cancer patients. Poster 2048 presented at the 31st Annual San Antonio Breast Cancer Symposium, December 10-14, 2008, San Antonio, TX.

44. Aft R, Naughton M, Trinkaus K, et al. Effect of zoledronic acid on disseminated tumour cells in women with locally advanced breast cancer: an open label, randomised, phase 2 trial. Lancet Oncol. 2010; 11(5):421-428.

45. Rack B, Juckstock J, Genss EM, et al. Effect of zoledronate on persisting isolated tumour cells in patients with early breast cancer. Anticancer Res. 2010;30(5):1807-1813.

46. Eidtmann H, de Boer R, Bundred N, et al. Efficacy of zoledronic acid in postmenopausal women with early breast cancer receiving adjuvant letrozole: 36-month results of the ZO-FAST study. Ann Oncol. 2010; 21:2188-2194.

47. de Boer R, Bundred N, Eidtmann H, et al. The effect of zoledronic acid on aromatase inhibitor-associated bone loss in postmenopausal women with early breast cancer receiving adjuvant letrozole: the ZO-FAST study 5-year final follow-up. Poster P5-11-01 presented at the 33rd Annual San Antonio Breast Cancer Symposium, December 8-12, 2010, San Antonio, TX.

48. Gnant M, Mlineritsch B, Schippinger W, et al. Endocrine therapy plus zoledronic acid in premenopausal breast cancer. $N$ Engl J Med. 2009;360(7):679-691

49. Gnant M, Mlineritsch B, Luschin-Ebengreuth G, et al. Long-term follow-up in ABCSG-12: Significantly improved overall survival with adjuvant zoledronic acid in premenopausal patients with hormonereceptor-positive early breast cancer. Abstract S1-2 presented at the CTRC-AACR San Antonio Breast Cancer Symposium, December 6-10, 2011, San Antonio, TX.

50. Coleman RE, Marshall H, Cameron D, et al. Breast-cancer adjuvant therapy with zoledronic acid. $N$ Engl J Med. 2011;365(15):1396-1405. 
51. Mystakidou K, Katsouda E, Parpa E, Kelekis A, Galanos A, Vlahos L. Randomized, open label, prospective study on the effect of zoledronic acid on the prevention of bone metastases in patients with recurrent solid tumors that did not present with bone metastases at baseline. Med Oncol. 2005;22(2):195-201.

52. Zaghloul MS, Boutrus R, El-Hossieny H, Kader YA, El-Attar I, Nazmy M. A prospective, randomized, placebo-controlled trial of zoledronic acid in bony metastatic bladder cancer. Int J Clin Oncol. 2010;15(4):382-389.

53. Zarogoulidis K, Boutsikou E, Zarogoulidis P, et al. The impact of zoledronic acid therapy in survival of lung cancer patients with bone metastasis. Int J Cancer. 2009;125(7):1705-1709.

54. Aviles A, Nambo MJ, Neri N, Castaneda C, Cleto S, Huerta-Guzman J. Antitumor effect of zoledronic acid in previously untreated patients with multiple myeloma. Med Oncol. 2007;24(2):227-230.

55. Hamilton E, Clay TM, Blackwell KL. New perspectives on zoledronic acid in breast cancer: potential augmentation of anticancer immune response. Cancer Invest. 2011;29(8):533-541.

56. Boyle WJ, Simonet WS, Lacey DL. Osteoclast differentiation and activation. Nature. 2003;423(6937):337-342.

57. Roodman GD. Mechanisms of bone metastasis. N Engl J Med. 2004; 350(16):1655-1664.

58. Bachmann MF, Kopf M. The role of B cells in acute and chronic infections. Curr Opin Immunol. 1999;11(3):332-339.

59. Kim HH, Shin HS, Kwak HJ, et al. RANKL regulates endothelial cell survival through the phosphatidylinositol 3'-kinase/Akt signal transduction pathway. FASEB J. 2003;17(14):2163-2165.

60. Theill LE, Boyle WJ, Penninger JM. RANK-L and RANK: T cells, bone loss, and mammalian evolution. Annu Rev Immunol. 2002;20: 795-823.

61. Kartsogiannis V, Zhou H, Horwood NJ, et al. Localization of RANKL (receptor activator of NF kappa B ligand) mRNA and protein in skeletal and extraskeletal tissues. Bone. 1999;25(5):525-534.

62. Bone HG, Bolognese MA, Yuen CK, et al. Effects of denosumab treatment and discontinuation on bone mineral density and bone turnover markers in postmenopausal women with low bone mass. J Clin Endocrinol Metab. 2011;96(4):972-980.

63. Miller PD, Bolognese MA, Lewiecki EM, et al. Effect of denosumab on bone density and turnover in postmenopausal women with low bone mass after long-term continued, discontinued, and restarting of therapy: a randomized blinded phase 2 clinical trial. Bone. 2008; 43(2):222-229.

64. Stopeck A, Lipton A, Martin M, et al. Denosumab in patients with breast cancer and bone metastases previously treated with zoledronic acid or denosumab: results from the 2-year open-label extension treatment phase of a pivotal phase 3 study. Abstract P3-16-07 presented at the San Antonio Breast Cancer Symposium, December 6-10, 2011, San Antonio, TX.

65. Lipton A, Siena S, Rader M, et al. Comparison of denosumab versus zoledronic acid for treatment of bone metastases in advanced cancer patients: an integrated analysis of 3 pivotal trials. Poster 1249P presented at the 35th ESMO Congress, October 8-12, 2010, Milan, Italy.

66. Smith MR, Saad F, Coleman R, et al. Denosumab and bone-metastasis-free survival in men with castration-resistant prostate cancer: results of a phase 3, randomised, placebo-controlled trial. Lancet. 2012;379(9810): $39-46$.

67. US National Institutes of Health. Study to determine treatment effects of denosumab in patients with breast cancer receiving aromatase inhibitor therapy. Available from: http://www.clinicaltrials.gov/ct2/show/NCT0 0556374?term=NCT00556374\&rank=1. Accessed May 8, 2012.

68. US National Institutes of Health. ClinicalTrials.gov. Study of denosumab as adjuvant treatment for women with high risk early breast cancer receiving neoadjuvant or adjuvant therapy (D-CARE). Available from: http:/www.clinicaltrials.gov/ct2/show/NCT01077154?term=NCT010 77154\&rank=1. Accessed May 8, 2012.

69. Aapro M, Abrahamsson PA, Body JJ, et al. Guidance on the use of bisphosphonates in solid tumours: recommendations of an international expert panel. Ann Oncol. 2008;19(3):420-432.
70. Tanvetyanon T, Stiff PJ. Management of the adverse effects associated with intravenous bisphosphonates. Ann Oncol. 2006;17(6):897-907.

71. Maxwell C, Swift R, Goode M, Doane L, Rogers M. Advances in supportive care of patients with cancer and bone metastases: nursing implications of zoledronic acid. Clin J Oncol Nurs. 2003;7(4): 403-408.

72. Saad F, Brown JE, Van Poznak C, et al. Incidence, risk factors, and outcomes of osteonecrosis of the jaw: integrated analysis from three blinded active-controlled phase III trials in cancer patients with bone metastases. Ann Oncol. 2012;23(5):1341-1347.

73. Coleman R, Bundred N, de Boer R, et al. Impact of zoledronic acid in postmenopausal women with early breast cancer receiving adjuvant letrozole: Z-FAST, ZO-FAST, and E-ZO-FAST. Abstract 4082 presented at the 32nd Annual San Antonio Breast Cancer Symposium, December 9-13, 2009, San Antonio, TX.

74. Ellis GK, Bone HG, Chlebowski R, et al. Randomized trial of denosumab in patients receiving adjuvant aromatase inhibitors for nonmetastatic breast cancer. J Clin Oncol. 2008;26(30): 4875-4882.

75. Ripamonti CI, Maniezzo M, Campa T, et al. Decreased occurrence of osteonecrosis of the jaw after implementation of dental preventive measures in solid tumour patients with bone metastases treated with bisphosphonates. The experience of the National Cancer Institute of Milan. Ann Oncol. 2009;20(1):137-145.

76. Badros A, Terpos E, Katodritou E, et al. Natural history of osteonecrosis of the jaw in patients with multiple myeloma. J Clin Oncol. 2008;26(36):5904-5909.

77. Ruggiero SL, Dodson TB, Assael LA, Landesberg R, Marx RE, Mehrotra B. American Association of Oral and Maxillofacial Surgeons. Position paper on bisphosphonate-related osteonecrosis of the jaw 2009 update. Aust Endod J. 2009;35:119-130.

78. Launay-Vacher V. Epidemiology of chronic kidney disease in cancer patients: lessons from the IRMA study group. Semin Nephrol. 2010; 30(6):548-556.

79. Launay-Vacher V, Izzedine H, Rey JB, et al. Incidence of renal insufficiency in cancer patients and evaluation of information available on the use of anticancer drugs in renally impaired patients. Med Sci Monit. 2004;10(5):CR209-CR212.

80. Launay-Vacher V, Spano JP, Janus N, et al. Renal insufficiency and anticancer drugs in elderly cancer patients: a subgroup analysis of the IRMA study. Crit Rev Oncol Hematol. 2009;70(2):124-133.

81. Stevens LA, Li S, Wang C, et al. Prevalence of CKD and comorbid illness in elderly patients in the United States: results from the Kidney Early Evaluation Program (KEEP). Am J Kidney Dis. 2010;55(3 Suppl 2): S23-S33.

82. Launay-Vacher V, Oudard S, Janus N, et al. Prevalence of renal insufficiency in cancer patients and implications for anticancer drug management: the Renal Insufficiency and Anticancer Medications (IRMA) study. Cancer. 2007;110(6):1376-1384.

83. National Kidney Foundation. K/DOQI clinical practice guidelines for chronic kidney disease: evaluation, classification and stratification. Am J Kidney Dis. 2002;39 Suppl 1:S1-S266.

84. Lichtman SM, Villani G. Chemotherapy in the elderly: pharmacologic considerations. Cancer Control. 2000;7(6):548-556.

85. Sahni V, Choudhury D, Ahmed Z. Chemotherapy-associated renal dysfunction. Nat Rev Nephrol. 2009;5(8):450-462.

86. Launay-Vacher V, Janus N, Karie S, Deray G. Letter. Systemic anticancer therapy in gynecological cancer patients with renal dysfunction. Int $J$ Gynecol Cancer. 2007;17(6):1340-1341.

87. Bondronat [summary of product characteristics]. Roche Diagnostics $\mathrm{GmbH}$ and Roche Products Limited. Available from: http://www. medicines.org.uk/EMC/printfriendlydocument.aspx?documentid=860 0\&compPublished. Revised August 9, 2011. Accessed May 8, 2012.

88. Bondronat [Professional Information Swiss Drug Compendium]. Roche Pharma (Schweiz) AG. Available from: http://www.kompendium.ch/ MonographieTxt.aspx?lang=fr\&MonType=fi. Published April, 2009. Accessed May 8, 2012. 
89. Dranitsaris G, Hatzimichael E. Interpreting results from oncology clinical trials: a comparison of denosumab to zoledronic acid for the prevention of skeletal-related events in cancer patients. Support Care Cancer. 2012;20(7):1353-1360.

90. Snedecor SJ, Carter JA, Kaura S, Botteman MF. Cost-effectiveness of zoledronic acid versus denosumab in prevention of skeletal-related events in castration-resistant prostate cancer metastatic to the bone. Abstract 4581 presented at the 2011 ASCO Annual Meeting, June 3-7, 2011, Chicago, IL.
91. Snedecor SJ, Carter JA, Kaura S, Botteman MF. Cost-effectiveness of denosumab versus zoledronic acid in the management of skeletal metastases secondary to breast cancer. Clin Ther. 2012;34(6):1334-1349.

92. Stopeck A, Rader M, Henry D, et al. Cost-effectiveness of denosumab vs zoledronic acid for prevention of skeletal-related events in patients with solid tumors and bone metastases in the United States. JMed Econ. 2012;15(4):712-723.

\section{Publish your work in this journal}

Cancer Management and Research is an international, peer-reviewed open access journal focusing on cancer research and the optimal use of preventative and integrated treatment interventions to achieve improved outcomes, enhanced survival and quality of life for the cancer patient The journal welcomes original research, clinical \& epidemiological studies, reviews \& evaluations, guidelines, expert opinion \& commentary, case reports \& extended reports. The manuscript management system is completely online and includes a very quick and fair peerreview system, which is all easy to use. Visit http://www.dovepress.com/ testimonials.php to read real quotes from published authors.

Submit your manuscript here: http://www.dovepress.com/cancer-management-and-research-journal 